INTERLUDE 1

\title{
Doing Research Differently? Putting Feminist Research Principles into Practice
}

\author{
Henri Myrttinen
}

\begin{abstract}
Ensuring that research is ethical and contributes to the reduction of inequalities, especially gendered, class-based and racialised power imbalances, is a central tenet of feminist research. The same, ideally, goes for peacebuilding processes. However, in spite of important and meaningful attempts to redress power imbalances, both academic research and peacebuilding work too often continue to be highly unequal endeavours. These imbalances persist between the global North and global South, but also within countries. For the most part, these imbalances are inescapable, for now at least, as both research and peacebuilding are in multiple ways entangled with broader, unequal power structures that are underpinned by patriarchy, militarism, neo-coloniality and neo-liberal capitalism. However, feminist-inspired research and peacebuilding work both do also create opportunities to analyse and question these power structures, to think and act beyond and to develop less extractive and more emancipatory alternatives and practices. This interlude examines how, as a transnational feminist research project, the researchers of this thematic volume sought to develop and foster such practices together with the communities involved in the research, and what this might mean for future research in times of the Covid-19 pandemic.
\end{abstract}

\section{Introduction}

A central tenet of feminist research is ensuring that it is ethical and contributes to the reduction of inequalities, especially gendered, class-based and racialised power imbalances. This was also at the heart of the broader project on gender and peacebuilding practices upon which this thematic volume is based. Ideally, the kinds of peacebuilding processes that the research presented here hopes to document and foster would similarly open spaces for and contribute to reducing gendered and other inequalities. However, in spite of important and meaningful attempts to redress power imbalances, including through participatory and feminist research practices, both academic research 
and peacebuilding work too often continue to be highly unequal endeavours. These imbalances persist between the global North and global South, but also within countries and societies. For the most part, these imbalances are inescapable, for now at least, as both research and peacebuilding are in multiple ways entangled with broader, unequal power structures that are underpinned by patriarchy, militarism, neo-coloniality and neo-liberal capitalism. At the same time, however, feminist-inspired research and peacebuilding work both do also create opportunities to analyse and question these power structures, to think and act beyond and to develop less extractive and more emancipatory alternatives and practices.

While these imbalances are nothing new, they have been thrown into sharp relief by the global covid-19 pandemic, be it through its direct impacts or its longer-term after-effects. The gendered, class-based and racialised inequalities in terms of access to secure incomes, of work-life balances, of who carries out socially reproductive labour versus financially compensated work and so on have increased dramatically over the course of the pandemic. The shift to socially distanced, internet-based communication has increased access for some (e.g. making it no longer necessary to apply for visas) but has also heightened barriers to participation for many others, be it in terms of the languages or the tools and ways of communication used. In the long term, responses to the pandemic carry within them - theoretically at least - the possibility of leading to a more equitable world, one in which priorities are reset, health and care work is valued, and security re-conceptualised as being about human rather than state security. In the short term however, gendered, class-based, racialised and other imbalances look to have been deepened by the pandemic.

Parallel to the pandemic, 2020 has also seen increased calls for decolonising academia and addressing its racialised power imbalances and biases, in part inspired by the global Black Lives Matter movement. While this push for academia to seriously reconsider its own structures and ways of working has been building for decades, it has arguably gained more saliency during the pandemic, with its highly unequal impacts. While many of the most prominent actions around decolonising academia have been around symbols, such as statues or names of institutions, the calls go much further. What is required is an honest reckoning of the role of academia in creating and upholding global imbalances in the past and in the present and of the need to diversify curricula, alongside decentring the global North, but also changing the ways in which academia functions - from the ways in which research is conducted to the way support staff are treated.

Our research project could not foresee the pandemic and its consequences; nor can we claim to have been at the forefront of struggles to radically change 
academia. Nonetheless, by adopting a feminist approach to research, and by working both by necessity and by design in a networked, partially decentralised, collaborative manner, our ways of researching did unintentionally give us a preview of what 'research at a distance' can look like and how gendered, racialised and institutionalised power imbalances can at least be ameliorated.

\section{$2 \quad$ Addressing Power Imbalances, Translating, Networking}

The long-term research project on gender and peacebuilding that this thematic volume draws upon brought together global South researchers and practitioners from Indonesia and Nigeria as well as their counterparts from the global North, based in Switzerland and the United Kingdom. Our approach to research explicitly sought to reduce power imbalances, to not be extractive and to be as emancipatory as possible. Nonetheless, it also ran up against its own limits in this respect, and remains embedded in global North-centred power structures. Each of our research members came with different skill sets, and different expertise, background knowledge and access to networks and gatekeepers. Some had experience and understanding at the local, practical level, others more at the theoretical level, and as a team we sought to ensure that these strengths were balanced, one not being valued over the other.

The project involved various levels of partnerships and brokering, each with their own inherent inequalities: between research participants and researchers, between researchers and local gatekeepers, between the lead research organisation and partners and between the donor and the grantees. While these deep-rooted imbalances cannot be overcome over the course of one project, they were not rendered invisible but rather addressed explicitly by the donor and all participating partners. From the outset, the participating researchers openly discussed strategies to mitigate imbalances to the degree possible, including giving back to communities participating in the research, having collaborative approaches to designing and implementing the research and analysis processes, co-authoring and/or co-editing all publications, moving beyond more conventional global North analytical frameworks, and building in opportunities for fostering more junior researchers, in particular from the global South. The donor too was explicit in encouraging a more egalitarian approach to research through its partnership criteria.

Inevitably, a research process such as this one also involves multiple levels and processes of translation, be it of concepts and theories or of life experiences. While the on-the-ground research took place in communities in various parts of Indonesia and Nigeria, the analysis was carried out in other locations 
on three continents-including Abuja, Geneva, London and Yogyakartaand by people who were not directly part of these communities. In the final instance, the research outputs utilise for the most part the current global lingua franca, English, a language that is the mother tongue of none of the respondents or research team members. Such processes create multiple ethical challenges in terms of ensuring that we remain true to the stories and testimonies we gathered, but also make these legible and shareable through frameworks of academic analysis.

Many of the analytical tools used for making our findings legible and comparable-be those in terms of the theoretical concepts or of the software used - are, however, very much products of the global North and as such may not always capture the conceptual frameworks or lived realities that define the lives of our research participants. The knowledge produced by this global North-based analysis is also often valued higher than 'local' knowledge, placing us as researchers into positions of privilege that require examining but also come with responsibilities, such as that of not devaluing our respondents' knowledge and experiences.

While it is often a cliché to talk about projects like this being mutual learning processes, this truly was the case for all of us involved in this research project. Beyond learning about each other's contexts, building South-South relationships as much as North-South ones, or developing new analytical skills as researchers, our project also explicitly sought to expand this circle of learning and of benefiting from it. Thus, we supported concrete, local-level genderresponsive peacebuilding efforts in Indonesia and Nigeria. These included, for example, supporting a Peace Museum in Aceh, Indonesia, and in Nigeria training informal security providers on gender issues. Beyond having validation sessions with participating communities, the project also sought to produce accessible outputs, such as a documentary film, as a means of 'giving back' to the research participants, albeit in a small way. This giving back was especially important in those communities that were suspicious of the motives of the research.

Being a transnational project, the analysis stage especially also relied heavily on communications technologies, which are by now-thanks to CoviD-19widespread but by no means available to everyone, especially in conflict-affected and marginalised communities. This differential access to languages and means of communication inevitably produces differences and hierarchies between the researchers and research participants. Furthermore, the majority of the research outputs of this project, be they academic papers, conference presentations, books or policy briefs, are far removed from the lived realities of our research participants — and often inaccessible to them, hidden behind paywalls, language 
barriers and, in the case of conferences and workshops, immigration restrictions and prohibitive travel costs. Nonetheless, the demands of donors and of academia of course apply to this project as well, and this means producing outputs for mainly global North academic and policy discussions. This is not negative per se, but again highlights the necessity for us as the interpreters and presenters of the material to act as ethically as possible.

\section{Security and Ethics of Conducting Research in Conflict-Affected} Societies

The field research for this project was conducted in communities affected by conflict. In some cases, that conflict had ended decades ago, in others it was simmering, but in all cases it was omnipresent in research participants' lives. This raised further questions around security and research ethics, and the degree to which research was possible or not, and on which issues. It also meant adapting methodologies and approaches so as to ensure the safety and security of everyone involved in the research process, not only researchers and research participants, but also those assisting in and facilitating throughout the process, including ensuring self-care when and where this was possible. In spite of all attempts to mitigate risks, researchers did need to navigate tensions and conflicts at times, as even national researchers encountered mistrust and occasionally hostility in some locations. A further sensitive area consisted of the balancing acts that are inherent to research on conflicts. This included presenting the findings so that they neither demonise and dehumanise perpetrators nor downplay acts of violence or deny their culpability. It also meant ensuring that those who suffered violence are not depicted as defined by victimhood only, devoid of agency. Furthermore, we sought to enable the emergence of those stories of conflict that have been drowned out by dominant narratives. Lastly, taking an explicitly feminist, pro-gender equality approach in conducting research with actors who do not always share these outlooks and values has required ensuring that we are respectful of their world views to the degree possible while not compromising on key feminist principles.

The outbreak of the global CoviD-19 pandemic has put at least a temporary end to conventional academic field research as well as to in-person academic and policy discussion forums. It is as yet unclear to what degree the 'new 
normal' will look like the 'old normal', when and if field research will be carried out to the same extent as previously and how much more interaction will happen online as opposed to in-person. There is an enormous risk that in the aftermath of the pandemic, financial resources will be diverted away from gender equality work, that inequalities will become more entrenched and that the working conditions in academia and NGO s will become even more precarious and only accessible to those who can afford them financially—so, to those who have other forms of income or are supported financially by someone. The crisis does, however, also provide opportunities for a rethinking of priorities as mentioned above, and forces us to see the interconnectedness of our lives and how the personal truly is political.

The aftermath of the pandemic will also force academics to rethink approaches to doing field research, not just in terms of measures such as using masks and hand sanitisers. For one, it will force researchers to recognise more clearly that they also pose a potential danger to research participants, be it as potential vectors of disease or otherwise, inverting the more common assumption of 'the field' posing a danger to researchers. Secondly, one of the main benefits - and often the only benefit — of field research for participants has been the opportunity to link up to broader debates and make their stories heard. Those conducting research should thus also think through how to better ensure that research participants can become and remain networked, should they wish to do so, within new, videoconferencing-based structures that are fast evolving. Ideally, these new ways of engaging can be more egalitarian, allowing for research participants to engage more directly with global networks, but this will also require investments in enabling this access. They may also lead to a need to rethink the current role of the researcher as the main transmitter and translator of such knowledge from 'the field' for global debates. This ideally opens up possibilities for the kind of decentring of knowledge, breaking down of established hierarchies, and pluralisation of voices that the movement to decolonise academia calls for. However, such outcomes cannot be taken for granted, and nor does such broadening of the debate render critical academic analysis obsolete. Instead, it will require more rather than less engagement, and also more time and resources.

In the aftermath of the pandemic, the research and academic community must also seriously take into account unequal possibilities with regard to being able to live up to ever-increasing work demands, depending on one's gender, age, living conditions, location, class, health and other factors. These differences have led to widening gulfs between researchers, benefiting those who are already in a more comfortable position while taking an increasing emotional, mental and economic toll on many others. While we should celebrate 
the achievements of feminist research and peacebuilding and celebrate resilience, we can neither close our eyes to nor remain silent about the emotionally, financially and physically draining impacts of this work, be they for activists, community members or researchers.

The research process that led to this book gave us an opportunity to try and test different, less top-down, less extractive and more egalitarian ways of approaching academic work, in line with the feminist principles that we sought to promote. The twin moments of the pandemic and the increased push for a decolonised academia have made the need to rethink and restructure our ways of working an immediate concern. Our experiences as a research project showed some of the ways in which this is possible: by having clear partnership criteria, by using networked approaches, by co-authoring and co-editing, by creating new opportunities for junior researchers, and by thinking through ways of 'giving back' more concretely and meaningfully to research participants. As we highlight in the introduction to this thematic volume, gender 'does work' as a logic: as a structuring logic, as an identity logic, as a resource for peacebuilding. All of these logics are intertwined with our research and with the work done by the peacebuilders with whom we studied and engaged. The more we are aware of these logics, of their inherent power imbalances and potentials, and the more we engage with them directly, the better we can try to build a feminist peace.

Our ways of 'giving back' were only initial steps, and in spite of them the project still remained embedded in broader global power structures. As academia starts moving into a post-pandemic world, there are opportunities for doing things fundamentally differently — be that reducing inequalities or further exacerbating them. We hope that our experiences can help advocate and show ways of attaining the former, rather than the latter.

\section{Recommended Further Reading}

Åhäll, L. and T. Gregory (eds.) (2015) Emotions, Politics and War (Abingdon and New York: Routledge).

Eriksson Baaz, M. and M. Utas (2019) 'Exploring the Backstage: Methodological and Ethical Issues Surrounding the Role of Research Brokers in Insecure Zones', Civil Wars, 21(2), pp. 157-178, Dor: 10.1080/13698249.2019.1656357.

Krystalli, R. and C. Enloe (2020) 'Doing Feminism: A Conversation Between Cynthia Enloe and Roxani Krystalli', International Feminist Journal of Politics, 22(2), pp. 289298, DOI: 10.108 o/14616742.2019.1678394. 
Rivas, A.-M. and B.C. Browne (2018) Experiences in Researching Conflict and Violence Fieldwork Interrupted (Bristol: Bristol University Press).

Rodríguez, C.O. (2018) Decolonizing Academia-Poverty, Oppression and Pain (Black Point: Fernwood Publishing).

Tuck, E. and K.W. Yang (2012) 'Decolonization is not a Metaphor', Decolonization: Indigeneity, Education \& Society, 1(1), pp. 1-40. 